\title{
Important risk factors for road accidents
}

\author{
Dilshod Imamaliev ${ }^{1 *}$, Aslidin Urakov ${ }^{1}$, Muzrob Darabov ${ }^{1}$ and Ruzigul Sayfutdinova ${ }^{1}$ \\ ${ }^{1}$ Tashkent State Transport University, 100167, Tashkent, Uzbekistan
}

\begin{abstract}
This article analyzes the relationship and influence of factors such as the population, the level of motorization, economic development, and the state of the state road network on the state of the risk of road accidents, including the level of mortality and road injuries, as well as the relevance of improving methods for assessing, managing and predicting the risk of accidents in road traffic. National indicators of the level of road deaths and injuries in different countries were studied. The relationship between road accidents and the level of motorization, income of the population, the state of the road network, and other indicators were revealed. The urgency of the problem of road accidents and the organization of measures to reduce the level of road accidents is emphasized. It also takes into account the special importance of forming conceptually new approaches to the task of improving the efficiency of public administration in the field of organization and maintenance of road traffic through the implementation of the Concept of Road Safety in the Republic of Uzbekistan for the period 2018-2022, which includes the following main directions: further improvement of the regulatory framework in the field of road safety, including significant strengthening of responsibility for gross violations of traffic rules; comprehensive improvement of road infrastructure, improving the quality of roads, creating reliable conditions for the safe movement of vehicles; improving the legal culture, the necessary knowledge, and skills of road users, strengthening their discipline.
\end{abstract}

\section{Introduction}

Road safety involves the quality of road traffic, determined by the level of accidents, and reflects the road users' degree of safety from road accidents and their consequences. On the other hand, road safety can be understood due to the safe interaction of road users between themselves and the environment.

Currently, in the Republic of Uzbekistan, all existing issues in the areas of the state and public administration systems, the judicial and legal structure, economy, industry, medicine, education and science, security, foreign policy, as well as priority areas for the development of social spheres are being considered in the framework of the action strategy for the five priority areas of development of the Republic of Uzbekistan in 2017-2021. Paragraph 4.3 is also considered a priority. "Implementation of targeted programs for the construction of affordable housing, development and modernization of road transport,

\footnotetext{
${ }^{1 *}$ Corresponding author: dilimshod@gmail.com
} 
engineering, communication and social infrastructure that improve the living conditions of the population": further construction and reconstruction of road infrastructure, primarily the development of regional highways, major and current repairs of inter-farm rural roads, streets of settlements. The road provides services to consumers. At the same time, the road infrastructure should provide convenient and safe driving conditions for road users. Traffic safety of cars and pedestrians. Road user's requirements for road infrastructure: safe and convenient traffic and reducing the severity of accidents when drivers and pedestrians make mistakes.[1]

In the system of measures to ensure individual safety, reliable road safety is becoming increasingly important.

For example, according to the UN World Health Organization Newsletter, about 1.35 million people die each year due to road accidents (Figure 1), and between 20 and 50 million people suffer non-fatal injuries, many of which lead to disability. Road accidents (hereinafter referred to as road accidents) cost most countries 3\% of their gross domestic product (GDP). More than half of those who die on the world's roads belong to "vulnerable road users" - pedestrians, cyclists, and motorcyclists. 93\% of road deaths occur in lowincome countries, although these countries account for approximately $60 \%$ of all vehicles in the world. Road traffic injuries are the leading cause of death in children and young adults aged 5-29 years [2].

The main reasons for this sad statistic on highways are the increase in the speed limit of vehicles, ignorance, and gross violation of the road rules by its participants. At the same time, if the violation of traffic rules by pedestrians threatens only their health, then similar actions of drivers of vehicles are fraught with serious consequences both for the drivers themselves and for other road users - drivers of other vehicles, their passengers and, in fact, for pedestrians.

\section{Materials and Methods}

At the same time, statistical indicators show that, every year on the republic's territory, there are on average about 9-10 thousand road accidents, including more than 2 thousand of them - with human victims.

The results of a detailed study of the complex of implemented measures in the field of road safety indicate the presence of several problems in the regulatory regulation of certain requirements for highways, which lead to a decrease in the efficiency of managing the forces and means of state bodies responsible for ensuring the safe movement of vehicles and pedestrians.

In particular, the issues of clearly defining the requirements for roads of international, national, and local significance and creating a modern and, in all respect's convenient infrastructure for their safe use, remain unresolved. 


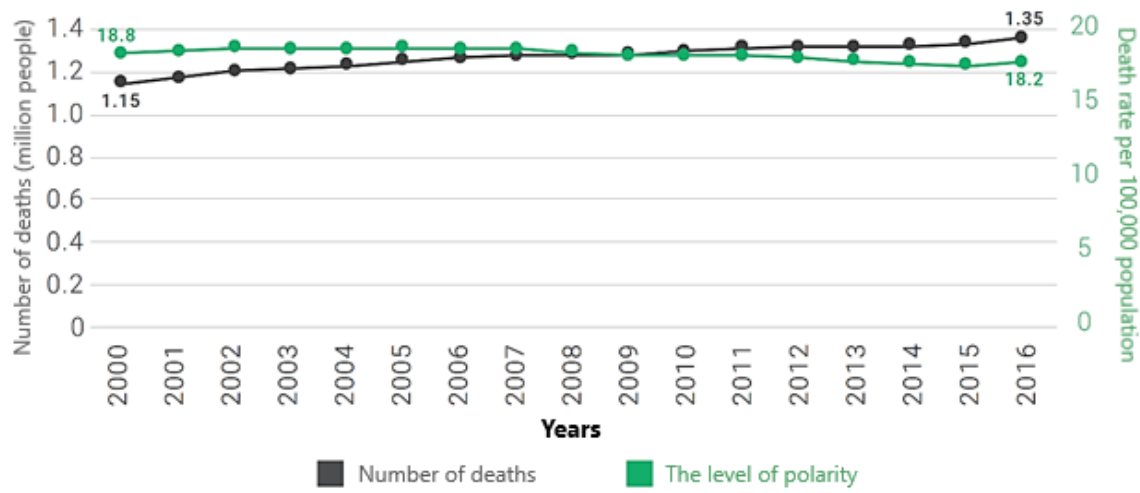

Fig.1. Number and rate of road traffic deaths per 100,000 population worldwide: 2000-2016. (Source: Calculation based on data from the 2018 WHO UN Report)

In this regard, of particular importance is the formation of conceptually new approaches to the task of improving the efficiency of public administration in the field of organization and maintenance of road traffic through the implementation of the Concept of Road Safety in the Republic of Uzbekistan for the period 2018-2022, which includes the following main areas: further improvement of the regulatory framework in the field of road safety, including significant strengthening of responsibility for gross violations of traffic rules; comprehensive improvement of road infrastructure, improving the quality of roads, creating reliable conditions for the safe movement of vehicles; improving the legal culture, the necessary knowledge and qualifications of road users, strengthening their discipline [3].

There is a complex relationship between road traffic injuries, the number of vehicles (Figure 2), and economic development in different countries (Figure 3). These connections have repeatedly become the object of research by Western scientists throughout the twentieth century. Periods of economic growth are usually accompanied by an increase in the mobility of people and an increase in the demand for vehicles. Also, the volume of traffic flow increases at this time, and with it, the number of accidents and injuries increases [4].

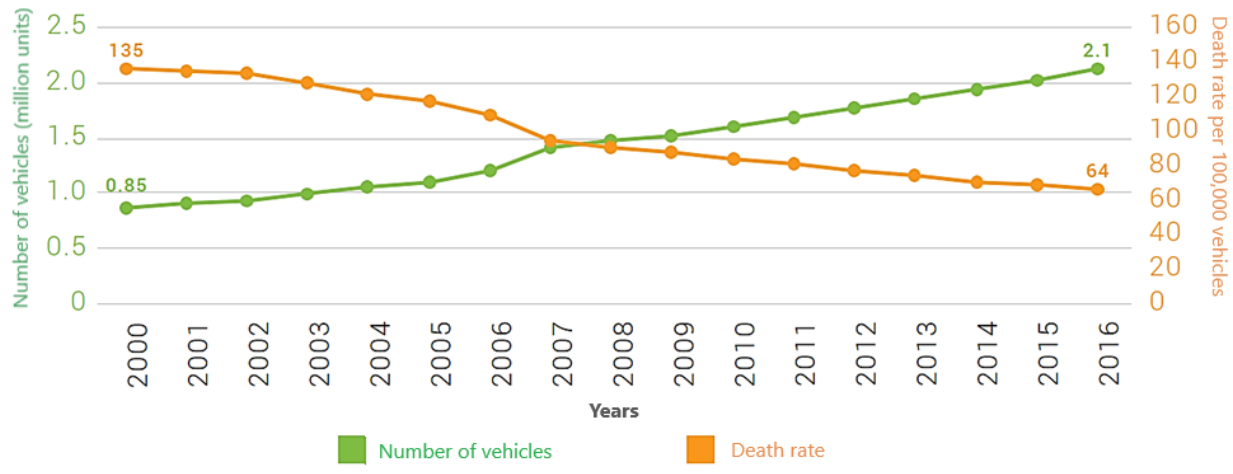

Fig.2. Number of motor vehicles and road traffic fatalities per 100,000 vehicles worldwide: 20002016. (Source: Calculation based on data from the 2018 WHO UN Report) 
With economic growth, the income of the population increases, which creates additional demand for all types of transport services, including the demand for passenger cars. But, apparently, there is a certain limit to the growth of motorization. The highest level of motorization is observed in the United States (843 passenger cars per 1000 population in 2010). In recent years, the annual car mileage and the level of motorization in the United States have stabilized. This level has not changed for quite a long time, and it has stabilized at the level of 45-50 thousand dollars of GDP per capita. Another interesting example is Norway, whose level of motorization for a long time does not exceed 700 passenger cars per 1000 population and where the GDP per capita is almost 100 thousand dollars. The difference between the United States and Norway most likely lies in the field of transport legislation, which has a more stringent framework in European countries [4].

International organizations recommend using the number of deaths per 100,000 of the country's population and the number of deaths per 10,000 vehicles to analyze road accidents. There are many studies that have examined the relationship between road traffic injuries and other socio-economic indicators. For example, there is a relationship between the overall death rate (deaths per 100,000 population) and GDP per capita.

The World Bank reports looking at data for 88 countries as the gross domestic product (hereinafter referred to as GDP) per capita increases. One of the main conclusions of this study was the identification of a sharp increase in the death rate per capita as GDP increases - but only at low levels of GDP per capita, up to a maximum of 6100-8600 US dollars. After reaching this maximum indicator, the per capita mortality rate begins to decline [5].

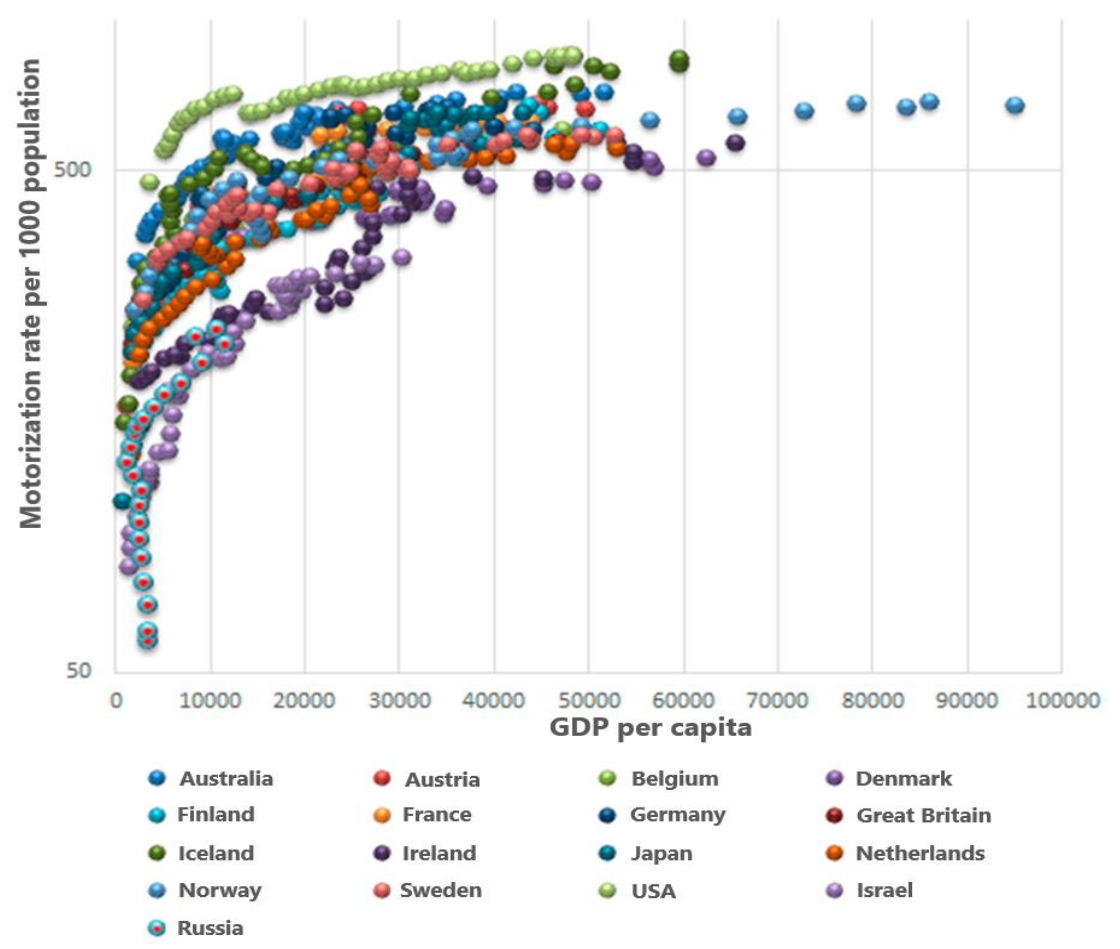

Fig. 3. The relationship between the level of motorization and GDP per capita in some countries of the world. (Source: Calculation based on IRTAD data for the period 1965-2010) 
When looking at the data from the World Bank's report on the classification of countries income levels, as well as comparing them with data on population size, the number of deaths due to road accidents, and the level of motorization, it can be seen that most of the indicators lie in countries with average per capita income (Figure 4).

The results of the above-mentioned World Bank report also showed that the death rate per vehicle declined sharply when GDP per capita exceeded $\$ 1,180$ (in the international value of the dollar for 1985). The presented empirical results show an important contribution of economic development to mobility, which leads to increased motorization and increased vulnerability.

Many modern studies have shown that road traffic injuries are multifaceted and not sufficiently studied; it reflects the dynamic development of many conditions and events, both at the economic and social level in all countries.

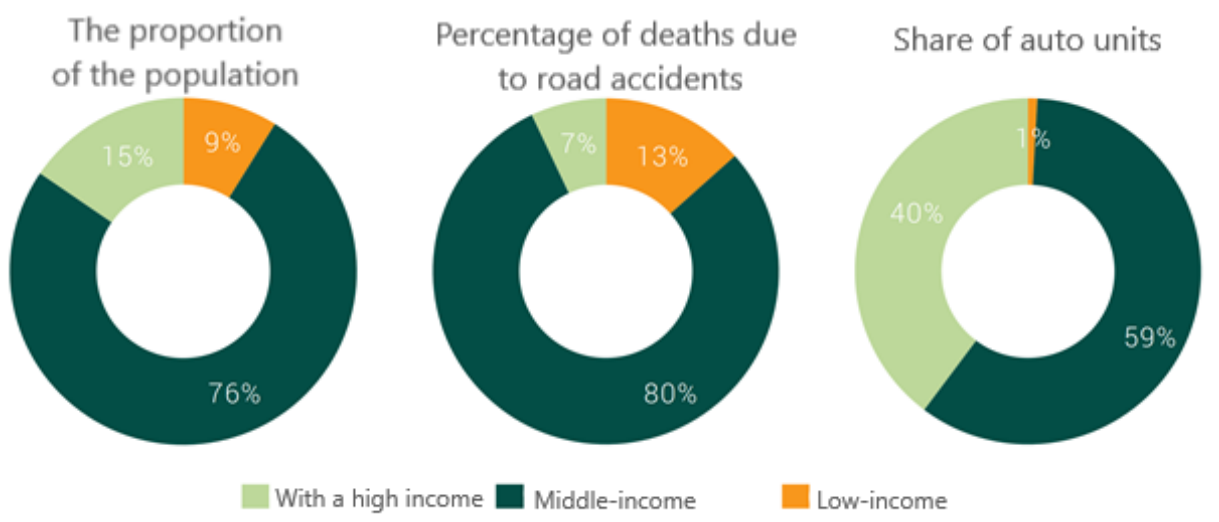

Fig.4. Percentage of the population killed in road accidents and registered vehicles by country income category, 2017. (Source: Calculation based on World Bank data on the classification of countries income levels for 2017)

A major role in ensuring traffic safety is also played by the highway's main technical and operational indicators. These include the geometric dimensions of the roadbed, the width and condition of the roadsides, the evenness, and roughness of the pavement, visibility on curves in the plan and longitudinal profile, the illumination of road sections at night, the presence of markings on the roadway, the quality of engineering equipment, the availability of controls following the actual traffic intensity. The influence of road conditions on traffic safety is laid down in the process of road design and is implemented in the process of road operation [7].

The level of development of the road network, which is characterized by compliance with the total length, density, distribution of roads by functional value and categories, socio-economic needs of society in road transport, plays a significant role in the formation of accidents. The disproportions in the development of the road network directly affect the unevenness of traffic loading and, accordingly, stimulate the increase in the risk of accidents, especially in areas where the capacity does not meet the observed traffic intensity [8].

Solving the problem of the lack of road network length is becoming more and more urgent, given the rapid growth of the number of road transport in the world ahead of the development of roads. 

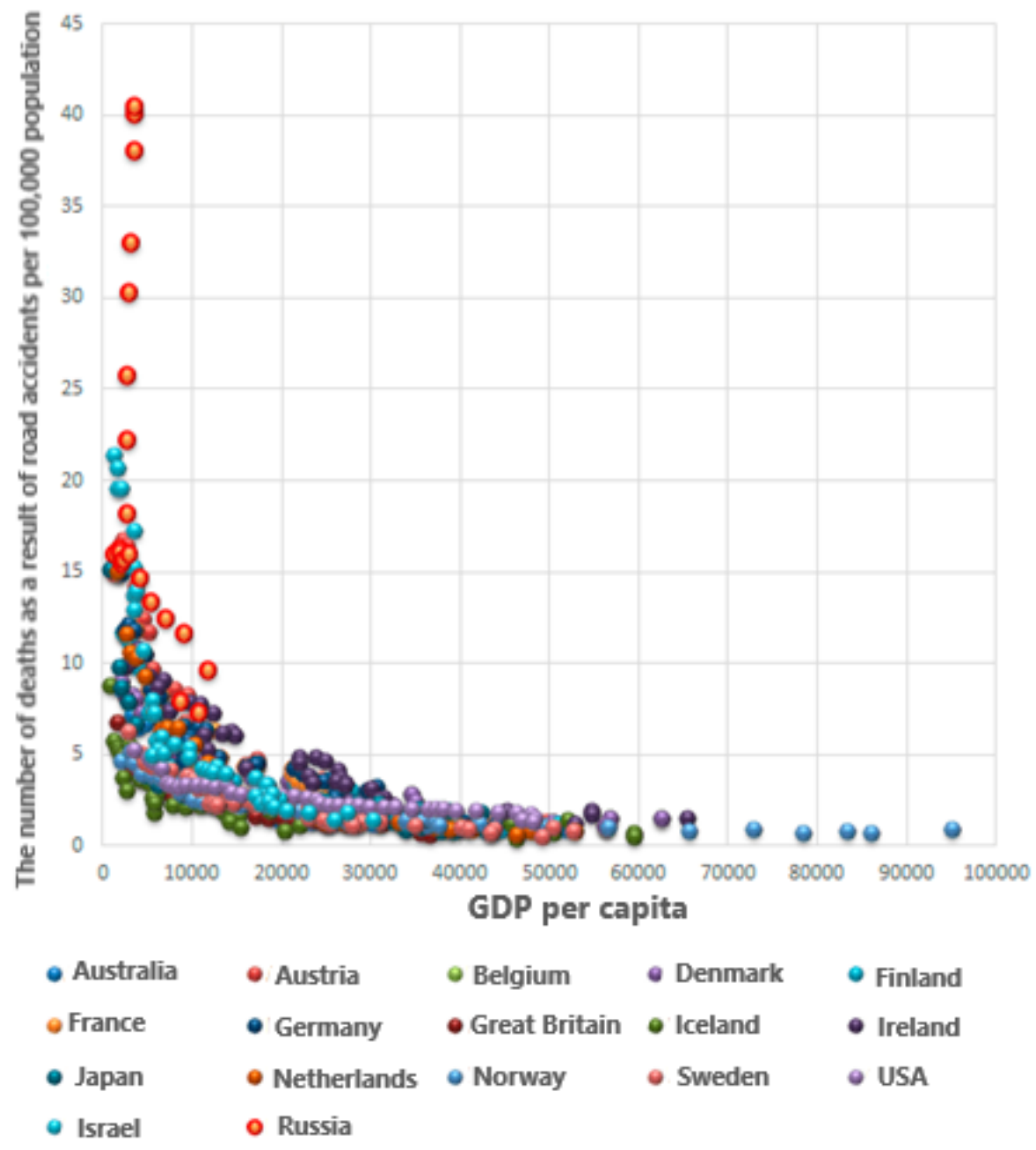

Fig.5. The relationship between the level of social risks (the number of deaths in road accidents per 100 thousand people) and GDP per capita. (Source: Calculation based on IRTAD data for the period 1965-2010.) 

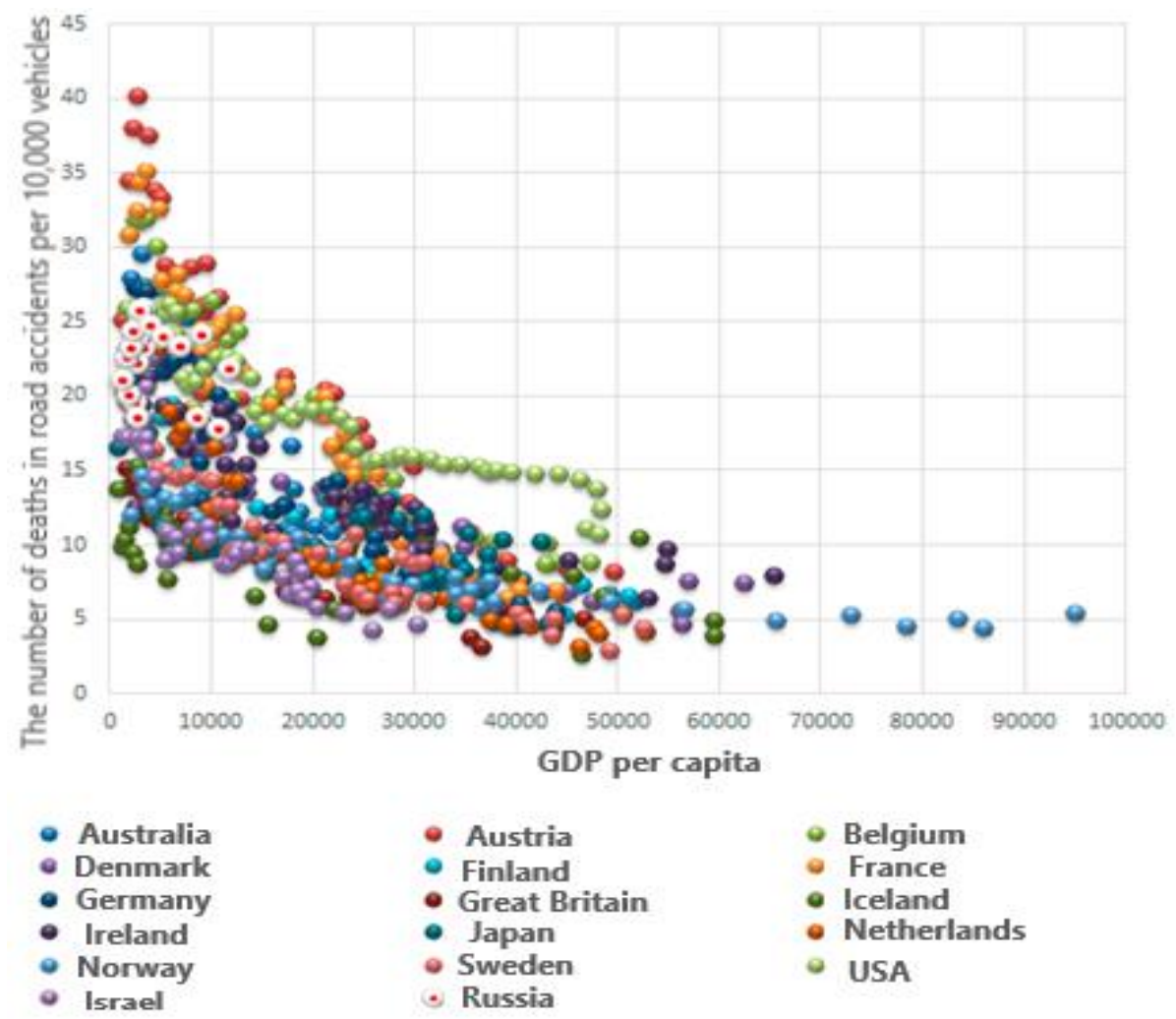

Fig.6. The relationship between the level of transport risks (the number of deaths in road accidents per 10 thousand vehicles) and GDP per capita. (Source: Calculation based on IRTAD data for the period 1965-2010.)

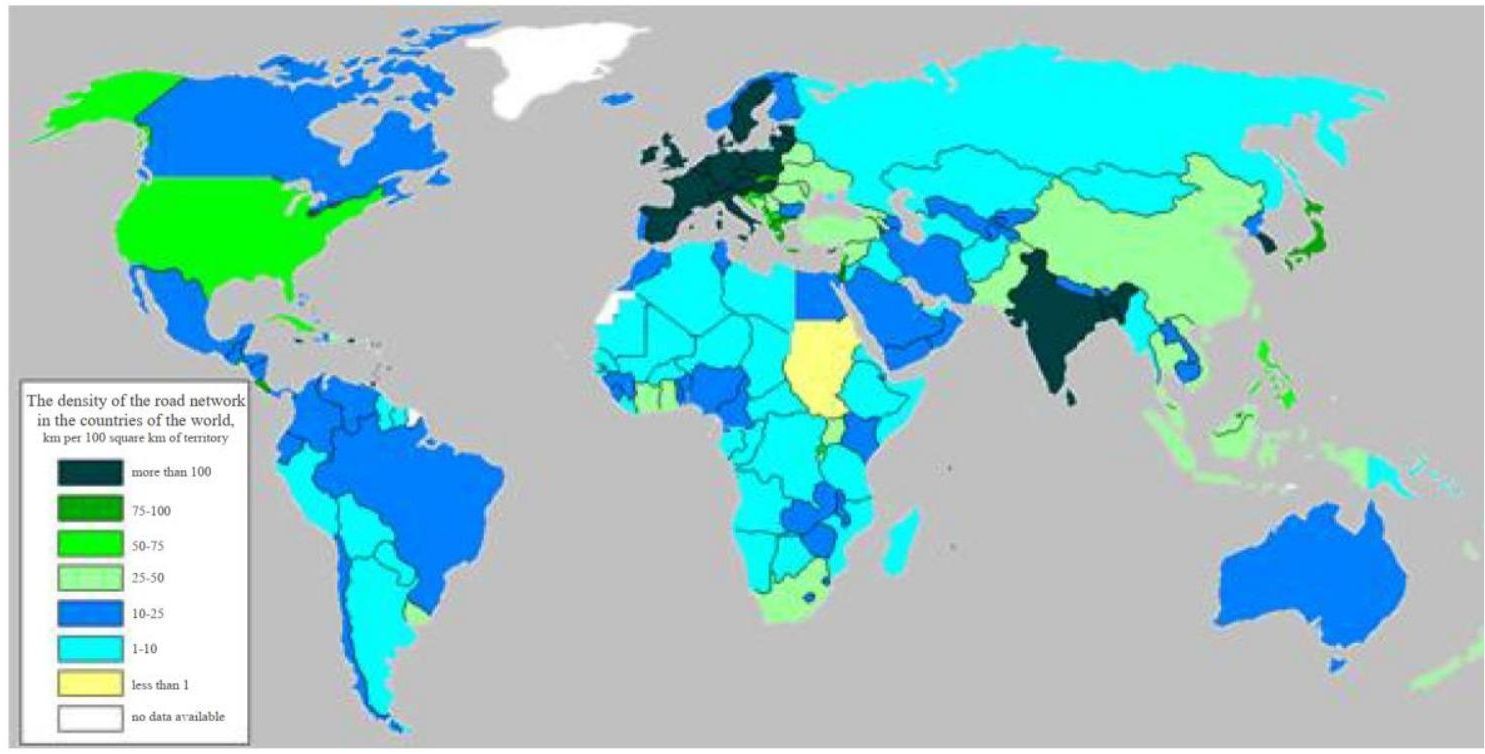

Fig.7. Distribution of countries by road network density, $\mathrm{km} / 100 \mathrm{~km} 2$ of territory. (Source: Data from the Food and Agriculture Organization of the Union Nations website). 
Increasing the density of the road network and bringing it into line with road transport needs is a fundamentally important point from the point of view of increasing the level of traffic safety.

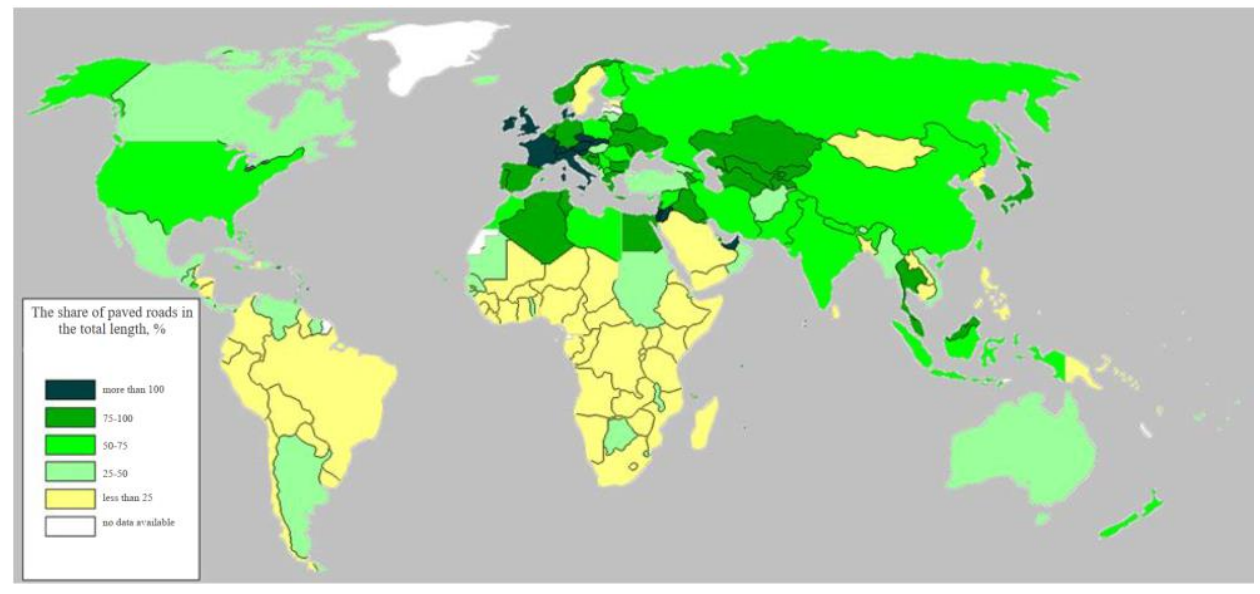

Fig.8. Distribution of countries by the share of paved roads in the total length, \%. (Source: Data from the Food and Agriculture Organization of the Union Nations website).

\section{Results and Discussion}

1. Based on the comparative analysis conducted in the study, a general pattern was established between the level of accidents and the level of motorization of the population:

- if the level of motorization of the population over 400 cars per 1 thousand inhabitants observed the lowest levels of accidents, which is characterized by the values in the accident rate less than $15 \%$-level security;

- at the level of motorization of the population in the range of 250-400 cars per 1 thousand inhabitants, accident rates are below the average values (the level of security $15-50 \%$ ), which corresponds to a low level of accidents;

- at the level of motorization of the population in the range of 100-250 cars per 1 thousand inhabitants, the accident rates are higher than the average values (the level of security of $50-85 \%$ ), which corresponds to the permissible level of accidents.

2. Where the road network density is less than $0.3 \mathrm{~km}$ of roads per $1 \mathrm{~km} 2$ of territory, the main indicator of accidents increases sharply. To improve road safety, timely construction of roads, expansion, and improvement of the roadway is necessary.

The study of the national road network of the Republic of Uzbekistan revealed the length of the unrepaired part of the road from the total length of the network. The density of highways by region was also revealed. According to the results of the study, the Syrdarya region, the Jizzakh region, the Samarkand region, the Kashkadarya region, the Surkhandarya region, the Bukhara region, the Navai Region, the Republic of Karakalpakstan, and the Tashkent region have less than $0.3 \mathrm{~km}$ of roads per $1 \mathrm{~km}^{2}$ (Table 1) [10]. 
Table 1. The length of the repaired highway and the density of the road network in the region.

\begin{tabular}{|c|c|c|c|c|c|c|}
\hline \multirow[b]{2}{*}{ № } & \multirow[b]{2}{*}{ Region } & \multicolumn{5}{|c|}{ Public highway, km } \\
\hline & & $\stackrel{5}{6}$ & 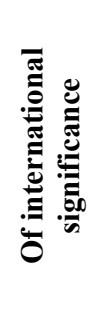 & 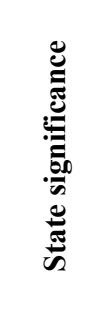 & 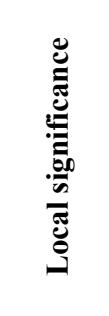 & 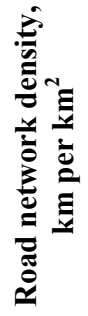 \\
\hline 1 & $\begin{array}{l}\text { Republic of } \\
\text { Uzbekistan }\end{array}$ & $\begin{array}{c}42695 \\
7527.4^{*}\end{array}$ & $\begin{array}{l}3981 \\
547.5\end{array}$ & $\begin{array}{l}14100 \\
2047.4\end{array}$ & $\begin{array}{l}24614 \\
4932.5\end{array}$ & 0.09 \\
\hline 2 & Andijan region & $\begin{array}{l}2463 \\
382.7\end{array}$ & $\begin{array}{c}103 \\
8\end{array}$ & $\begin{array}{l}800 \\
117\end{array}$ & $\begin{array}{l}1560 \\
257.7\end{array}$ & 0.58 \\
\hline 3 & Namangan region & $\begin{array}{l}3377 \\
780.6\end{array}$ & $\begin{array}{c}69 \\
0\end{array}$ & $\begin{array}{l}1048 \\
102.6\end{array}$ & $\begin{array}{c}2260 \\
678\end{array}$ & 0.42 \\
\hline 4 & Ferghana region & $\begin{array}{c}4031 \\
673\end{array}$ & $\begin{array}{c}202 \\
30\end{array}$ & $\begin{array}{l}873 \\
123\end{array}$ & $\begin{array}{c}2966 \\
520\end{array}$ & 0.59 \\
\hline 5 & Syrdarya region & $\begin{array}{l}1450 \\
376.9\end{array}$ & $\begin{array}{c}259 \\
46\end{array}$ & $\begin{array}{l}505 \\
85.6\end{array}$ & $\begin{array}{c}6866 \\
245.3\end{array}$ & 0.28 \\
\hline 6 & Jizzakh region & $\begin{array}{c}2601 \\
251\end{array}$ & $\begin{array}{c}168 \\
6\end{array}$ & $\begin{array}{c}1431 \\
156\end{array}$ & $\begin{array}{c}1002 \\
89\end{array}$ & 0.12 \\
\hline 7 & Samarkand region & $\begin{array}{l}4097 \\
855\end{array}$ & $\begin{array}{c}385 \\
95\end{array}$ & $\begin{array}{c}979 \\
95\end{array}$ & $\begin{array}{c}2733 \\
665\end{array}$ & 0.24 \\
\hline 8 & Kashkadarya region & $\begin{array}{c}3427 \\
734\end{array}$ & $\begin{array}{c}425 \\
46\end{array}$ & $\begin{array}{l}890 \\
265\end{array}$ & $\begin{array}{c}2112 \\
423\end{array}$ & 0.12 \\
\hline 9 & $\begin{array}{l}\text { Surkhandarya } \\
\text { region }\end{array}$ & $\begin{array}{c}2843 \\
478\end{array}$ & $\begin{array}{c}351 \\
32\end{array}$ & $\begin{array}{l}990 \\
200\end{array}$ & $\begin{array}{c}1502 \\
246\end{array}$ & 0.13 \\
\hline 10 & Bukhara region & $\begin{array}{c}4101 \\
501\end{array}$ & $\begin{array}{l}540 \\
113\end{array}$ & $\begin{array}{c}1155 \\
149\end{array}$ & $\begin{array}{c}2406 \\
239\end{array}$ & 0.10 \\
\hline 11 & Navai region & $\begin{array}{c}3917 \\
711\end{array}$ & $\begin{array}{c}302 \\
34\end{array}$ & $\begin{array}{c}2490 \\
290\end{array}$ & $\begin{array}{c}1125 \\
387\end{array}$ & 0.03 \\
\hline 12 & Haresm region & $\begin{array}{l}2210 \\
456.5\end{array}$ & $\begin{array}{c}113 \\
0\end{array}$ & $\begin{array}{c}706 \\
233.5\end{array}$ & $\begin{array}{c}1391 \\
223\end{array}$ & 0.35 \\
\hline 13 & $\begin{array}{l}\text { Republic of } \\
\text { Karakalpakstan }\end{array}$ & $\begin{array}{c}4213 \\
469\end{array}$ & $\begin{array}{l}664 \\
109\end{array}$ & $\begin{array}{c}992 \\
92\end{array}$ & $\begin{array}{c}2557 \\
268\end{array}$ & 0.02 \\
\hline 14 & Tashkent region & $\begin{array}{l}3965 \\
858.7\end{array}$ & $\begin{array}{l}400 \\
28.5\end{array}$ & $\begin{array}{l}1241 \\
138.7\end{array}$ & $\begin{array}{l}2324 \\
691.5\end{array}$ & 0.25 \\
\hline
\end{tabular}

*An unrepaired part of a public highway.

To reduce the level of risk during operational work on road sections of streets, it should be carried out taking into account:

- composition, traffic intensity, and road conditions;

- composition, types, and terms of work production;

- applied schemes of complex mechanization. including the use of the global navigation satellite system;

- availability of local road construction materials;

- natural and climatic conditions;

- terrain, geological and hydrological conditions. soil class; 
- compliance with traffic management schemes in the area of repair work with road safety;

- compliance with technological solutions with sanitary standards that ensure safety from contamination of the drain and underground water, the formation of thermokarst, erosion, ice, and other harmful processes [12].

\section{Conclusions}

In conclusion, it can be noted that international experience shows that in recent years in European countries with well-developed motorization with high GDP and the level density of the road network, a national policy, and programs in the field of road safety in the medium and long term. In addition to the general problems and methods of their solutions, targets characterizing road safety are identified. This must include experience in the implementation of similar programs in other countries with a similar rate of car ownership, income level of the population, the condition, and development of the road network [9].

In domestic practice, an example of such an approach is the State Program "On additional measures to implement the Concept of Road Safety in the Republic of Uzbekistan for 2018-2022", which includes the following areas: - implementation of public-private partnership in the field of road safety and the creation of modern road infrastructure; - implementation of integrated traffic monitoring systems and intelligent video cameras; - organization of paid parking spaces and paid car parking; - construction of roadside infrastructure facilities with the use of landscaping along public roads.

Finally, we can say that the problem of road safety is multifaceted; it is directly related to the economic and social spheres of our society. It is safe to say that the stability of our social life and its normal functioning depends on the degree of solving this problem [11].

\section{References}

1. Imamaliev D.M.. Sadikov I.S.. Urakov A.H. Sadikov A.I, Systematic approach to forecasting and managing road safety risks. Architecture and construction problems. Scientific and technical journal. SCAI. 2019. 3.pp 146-148. (2019).

2. Global status report on road safety 2018. - Geneva: World Health Organization. 2018. - ISBN 978-92-4-1565684. p 5.

3. "On additional measures to implement the Concept of Road Safety in the Republic of Uzbekistan for 2018-2022". Resolution of the Cabinet of Ministers of the Republic of Uzbekistan No. 990 of December 5. 2018. Tashkent city. (2018)

4. Fattakhov T. Motorization and transport risks. Electronic resource. http://www.demoscope.ru/weekly/2014/0593/tema03.php

5. World report on road traffic injury prevention. - Geneva: World Health Organization. 2004. ISBN 92 156260 9. p 97. (2004).

6. Statistics of road traffic accidents in Europe and North America, Economic commission for Europe. - Geneva: United Nations. Vol. XLVI. p 139. (2001)

7. Terekhova L. O.. Labanov P. A. Influence of road conditions on traffic safety. Minsk. BNTU. Data 
8. "The impact of the development and state of the road network on the level of traffic safety on the roads of Russia". Overview information. Moscow.4. pp. 25-46. (2003).

9. Chvanov V. V. Comparative analysis of international statistical data on road accidents. - M, p. 111-120.- (Collection of scientific papers/MADI (GTU). (2000).

10. Open data of the State Committee on Highways of the Republic of Uzbekistan. Electronic resource. https://www.uzavtoyul.uz/uz/page/avtomobil-yo-llariningholatini-ko-rsatuvchi-ochiq-elektron-xaritasi.html.

11. Sadikov I. S.. Imamaliev D. M. Traffic accidents are the main risk factors for occurrence. Scientific and technical journal. TIDCOH. (2) pp 20-25. (2020)

12. Imamaliev D.M.. Sadikov I.S.. Urakov A.H.. Sadikov A.I. Systematic approach to forecasting and managing road safety risks. Architecture and construction problems. Scientific and technical journal. SCAI. (3). pp 146-148. (2019). 